\title{
A Reliability Test System For Educational Purposes - Probabilistic Transient Stability Studies
}

\author{
S.M. Al-Dhalaan, Member IEEE \\ Director General for Research \\ General Organization for Technical Education \& Vocational Training
}

\begin{abstract}
The probabilistic nature of the transient stability problem and the need to include in the analysis the probabilities associated with the initiating factors such as the type, location and clearance of faults have been recognized for some time. These factors, however, are rarely if ever, introduced into the basic building blocks associated with a power system education program. This paper extends a published educational test system by including the system data required to conduct transient stability analysis and hence evaluate the security of this system. The probabilistic transient stability methodology and the resulting indices presented in this paper provide a basic understanding of probabilistic assessment of transient stability and can easily be included in a power system reliability or stability teaching program.
\end{abstract}

\section{INTRODUCTION}

The fundamental objective of an electric power system is to supply its customers with electric energy as economically as possible and with a reasonable assurance of continuity and quality. The increased dependence of modern societies on electric energy has led to the recognition of the need for both high reliability of service and for methods of assessing and improving power system reliability. It is impossible to attain a system reliability of one hundred percent, regardless of the amount of time, effort and money spent. Power system designers, planners and scientists have, therefore, always directed their efforts towards achieving the maximum possible system reliability at an affordable cost.

In general, the term reliability can be defined as a measure of the overall ability of a system to perform its particular function [2]. The term reliability, however, has a wide range of meaning when applied to power systems. A simple but reasonable subdivision of system reliability is system adequacy and system security [3]. System adequacy relates to the existence of sufficient facilities within the system to satisfy the consumer load demand. These include the necessary facilities to generate sufficient energy and the associated facilities to transmit and distribute this energy to the different customer load points. System

Manuscript received from Dr. S.M.Al -Dhalaan

Accepted on : $16 / 6 / 2001$

Engineering Research Journal Vol 24,No 3, 2001 Minufiya University, Faculty of

Engineering , Shebien El-Kom , Egypt , ISSN 1110-1180 
adequacy, therefore, is associated with static conditions which do not include system disturbances. System security, on the other hand, relates to the ability of a system to respond to disturbances and perturbations arising within that system. System security, therefore, involves the dynamic behavior of the system and may require dynamic studies such as transient stability analysis which involves detailed modeling of the power system. It is clear that adequacy assessment and security analysis deal with quite different reliability issues and involve different assessment techniques. This paper deals with probabilistic transient stability assessment which falls in the domain of security evaluation.

Modern power system education programs usually include a reliability component in their curriculum. In some schools this is a separate course, while in others it is part of a general course or a segment of a special topics component. In nearly all cases, the content is in the power system adequacy domain. Virtually all undergraduate and graduate power engineering programs, however, include transient stability considerations in their curriculum [4]. In many cases, these are restricted to the rudiments of stability analysis while other schools and particularly those with research activities in this area, devote considerable time and attention to this subject. Transient stability is an essential element of power system security and this aspect should be recognized and included in both basic and advanced teaching programs. It appears logical therefore that a student should also consider the stochastic nature associated with system parameters and behavior and recognize that many of the parameters associated with transient stability have a probabilistic dimension.

In general, there are two main published techniques for probabilistic assessment of transient stability. The first technique utilizes the conditional probability theorem in analytically evaluating the probability of stability [5-10]. The second technique utilizes Monte-Carlo simulation [11]. In order to evaluate the security of composite power systems [12], many computer runs are required to examine the system performance for different system configurations. This can involve considerable computer time. The objective of this paper is to present a relatively simple model which can be used in an educational framework to examine the probabilistic nature of transient stability. The computation time requirements can be reduced by using simple but suitable techniques for the determination of transient stability and simplifying the system modeling by incorporating the major factors and neglecting additional considerations. The test system illustrated in this paper incorporates these considerations.

Many of the factors involved in transient stability evaluation are probabilistic in nature and while it is difficult to obtain the required statistics, the fundamental role that these factors play in the likelihood of power system instability should be known and appreciated. This paper introduces the basic concepts associated with a probabilistic framework for transient stability assessment. The framework is independent of the actual numerical procedure [4] used for transient stability analysis and is illustrated by application to a previously published educational test system [1]. This paper adds the necessary stability related information to the previously published data. 


\section{STABILITY FACTORS}

The traditional design of a power system includes testing the stability of the system under specified basic contingencies such as a three-phase fault near generator buses or on particular transmission lines. This "worst case" approach has been used successfully by most power utilities. It is obvious that a wide range of contingencies are possible at any location in the system. This introduces the realization that a stochastic approach could be used in the analysis to include the probabilities associated with all possible contingencies in order to obtain a more realistic appraisal of the system stability. There are several uncertainties that have considerable effect in the probabilistic assessment of transient stability. These are:

\section{Type of Fault}

There are two basic fault types that occur in power system operation, open circuit faults and short circuit faults. The second type is more common and has in general, a more severe impact on the system. Short circuit faults that affect transient stability can be classified into the four categories of three phase, double line to ground, double line and single line to ground faults. The probability of occurrence of each of these can vary significantly from one system to another as it depends highly on the system configuration, weather, and the geographical location of the system.

\section{Location of Fault}

The resulting severity of a given fault tends to diminish as the distance between the fault location and the generating units increases. Faults near generator buses are the most severe faults in the system. The location of the fault is probabilistic, and can be represented by the probability distribution of fault occurrence. The probability distribution for fault location will be different for each line in the system and from one system to another and can be determined from statistical data on the system.

\section{Fault Clearing Phenomena}

Fault clearing time is the most important factor affecting transient stability. The more quickly a fault is cleared, the more likely the system is to be stable. On the other hand, if a fault remains. on the system for a long time before it is cleared, the system may experience transient stability problems. The operating time of the breakers required to clear a fault is a combination of the main protection time, the backup protection time and the signaling time. The combination of these two times is a random variable. The probability distribution of fault clearing time can be obtained by modeling the protection system involved.

\section{System parameters and operating conditions}

System stability is affected by all of the physical elements in the system. The actual physical system parameters are non-probabilistic. The system operation at some time in future, however, is probabilistic in nature and affects the transient stability of the system. 


\section{A PROBABILISTIC INDEX FOR TRANSIENT STABILITY}

Reference 5 proposes that probabilistic factors should be included in the evaluation of power system stability. The first and the most difficult step in the probabilistic approach is to collect statistical data on system faults such as fault types, locations, and clearing times. Each of these three factors are mutually exclusive and therefore the conditional probability approach can be used to assess system transient stability.

Figure 1 shows a possible probability density function for the fault clearing time. If the critical clearing time (CCT) is the maximum time in which the fault must be cleared, then the shaded area in this figure represents the probability of stability $P_{i j}$ for a fault type $i$ at a location $j$. Using the conditional probability approach, the probability of stability (PST) for all fault types $(I)$ at all possible locations $(J)$ of line $k$ is given by the following equation:

$$
P S T_{k}=\sum_{j=1}^{J} \sum_{i=1}^{J} P_{i j} P_{i} P_{j}
$$

where:

$P_{i j}$ the probability of stability if a fault of type $\mathrm{i}$ occurs at location $\mathrm{j}$ of line $\mathrm{k}$,

$P_{i}$ the probability of having a fault of type $\mathrm{i}$ occur at location $\mathrm{j}$ of line $\mathrm{k}$ and

$P_{j}$ the probability of having a fault at location $\mathrm{j}$ of type $\mathrm{i}$ on line $\mathrm{k}$.

Equation (1) can be used to calculate stability indices for each line in the system. These stability indices can then be used to calculate a single stability index for the overall system.

\section{TRANSIENT STABILITY DATA FOR THE RBTS}

Figure 2 shows the single line diagram for the reliability test system (RBTS). The RBTS has a total installed capacity of $240 \mathrm{MW}$ provided by eleven generating units as shown in Figure 2. The basic line data and bus data are given in Table I and Table II respectively.

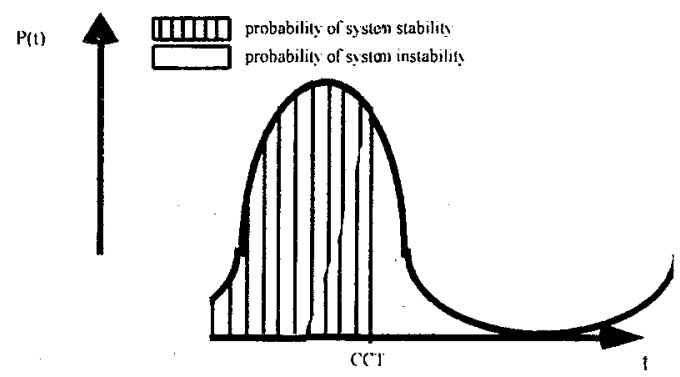

Figure 1: Probability density function of the fault clearing time 


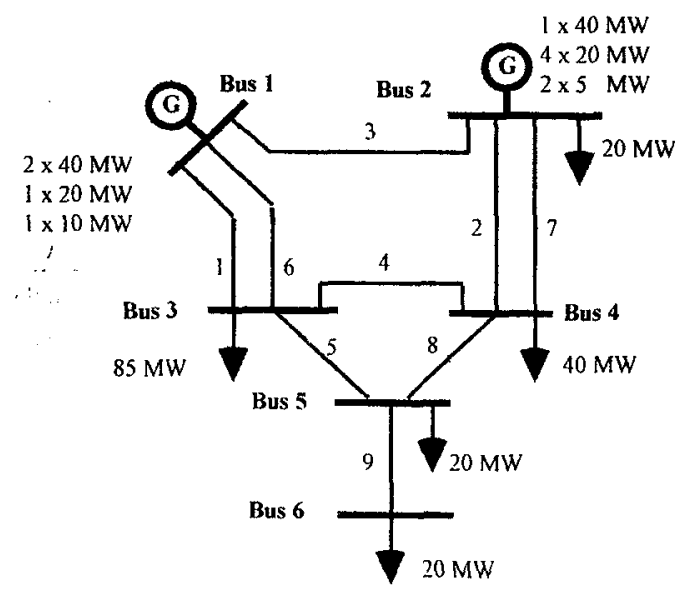

Figure 2: Single line diagram of the RBTS

The data provided in Reference 1 does not include the information required to conduct basic transient stability studies on the RBTS. These additional data are as follows.

\section{Deterministic Data:}

Transmission lines: The negative sequence impedances for the transmission lines are equal to the positive sequence values given in Table I. The zero sequence impedances are assumed to be three times the positive sequence values.

Generators: The classical model parameters are provided for the RBTS. The positive, negative and zero sequence data are given in Table III together with the unit rated power and inertia constants.

Table I: Line data (p.u.)

\begin{tabular}{|c|c|c|c|c|}
\hline \multirow{2}{*}{$\begin{array}{c}\text { Line No. } \\
1\end{array}$} & \multicolumn{1}{c}{$\mathrm{R}$} & \multicolumn{1}{c|}{$\mathrm{X}$} & $\mathrm{B} / 2$ & $\mathrm{I}$-rat. \\
\cline { 2 - 5 } & 0.0342 & 0.1800 & 0.0106 & 0.85 \\
\hline 2 & 0.1140 & 0.6000 & 0.0352 & 0.71 \\
\hline 3 & 0.0912 & 0.4800 & 0.0282 & 0.71 \\
\hline 4 & 0.0228 & 0.1200 & 0.0071 & 0.71 \\
\hline 5 & 0.0228 & 0.1200 & 0.0071 & 0.71 \\
\hline 6 & 0.0342 & 0.1800 & 0.0106 & 0.85 \\
\hline 7 & 0.1140 & 0.6000 & 0.0352 & 0.71 \\
\hline 8 & 0.0228 & 0.1200 & 0.0071 & 0.71 \\
\hline 9 & 0.0228 & 0.1200 & 0.0071 & 0.71 \\
\hline
\end{tabular}


Table II: Bus data (p.u.)

\begin{tabular}{|c|c|c|c|c|c|c|}
\hline \hline Bus & Pload & Qload & P gen. $_{\text {gmax }}$ & Qmin & V \\
\cline { 2 - 7 } 1 & 0.000 & 0.000 & 1.000 & 0.500 & -0.40 & 1.05 \\
\hline 2 & 0.200 & 0.000 & 1.200 & 0.750 & -0.40 & 1.05 \\
\hline 3 & 0.850 & 0.000 & 0.000 & 0.000 & 0.000 & 1.00 \\
\hline 4 & 0.400 & 0.000 & 0.000 & 0.000 & 0.000 & 1.00 \\
\hline 5 & 0.200 & 0.000 & 0.000 & 0.000 & 0.000 & 1.00 \\
\hline 6 & 0.200 & 0.000 & 0.000 & 0.000 & 0.000 & 1.00 \\
\hline
\end{tabular}

Table III: Additional deterministic generator data for the RBTS

\begin{tabular}{|c|c|c|c|c|c|}
\hline $\begin{array}{c}\text { Unit } \\
\text { No. }\end{array}$ & $\begin{array}{c}\mathrm{X}^{\prime} \mathrm{d} \\
(\text { p.u. })\end{array}$ & $\begin{array}{c}\mathrm{X}_{2} \\
\text { (p.u.) }\end{array}$ & $\begin{array}{c}\mathrm{X}_{0} \\
(\text { p.u. })\end{array}$ & $\begin{array}{c}\text { Rating } \\
(\mathrm{MW})\end{array}$ & $\begin{array}{c}\mathrm{H} \\
(\mathrm{s})\end{array}$ \\
\cline { 2 - 6 } 1 & 0.20 & 0.10 & 0.08 & 40.0 & 5.0 \\
\hline 2 & 0.20 & 0.10 & 0.08 & 40.0 & 5.0 \\
\hline 3 & 0.10 & 0.05 & 0.03 & 10.0 & 3.0 \\
\hline 4 & 0.15 & 0.10 & 0.05 & 20.0 & 4.0 \\
\hline 5 & 0.10 & 0.05 & 0.03 & 5.0 & 1.0 \\
\hline 6 & 0.10 & 0.05 & 0.03 & 5.0 & 1.0 \\
\hline 7 & 0.20 & 0.10 & 0.08 & 40.0 & 5.0 \\
\hline 8 & 0.15 & 0.10 & 0.05 & 20.0 & 4.0 \\
\hline 9 & 0.15 & 0.10 & 0.05 & 20.0 & 4.0 \\
\hline 10 & 0.15 & 0.10 & 0.05 & 20.0 & 4.0 \\
\hline 11 & 0.15 & 0.10 & 0.05 & 20.0 & 4.0 \\
\hline
\end{tabular}

\section{Probabilistic Data:}

The probabilities associated with the type, location and fault clearing times are shown in Tables IV, V and VI. Table IV presents the fault occurrence probabilities given a fault occurs. Table $\mathrm{V}$ shows the assumed probability distribution of fault location on the transmission lines. The probability distribution for the fault type, location are the same for all the transmission lines. The fault clearing times are assumed to be normally distributed. The mean and the standard deviation of the fault clearing time probability distributions are given in Table VI. All given tables values have a 100 MVA base.

\section{PROBABILISTIC TRANSIENTT STABILITY ASSESSMENT IN THE RBTS}

In practical systems, the load is not constant throughout the year. The assumption that the load stays at the peak value is used to give reliability values designated as annualized indices. The hourly annual load duration curve for the system can be used to calculate annual indices. The most common system load representation in reliability studies, is to use multi-step model, as a more detailed representation can require considerable computation time. A reduced and therefore approximate load model can be used quite successfully to obtain acceptable annual indices. The number of steps required in the analysis depends 
on the shape of the load duration curve and the required level of accuracy. In order to calculate the annual indices and to show the effect of multi-step load modeling, a "seven-step" load model for the RBTS load duration curve (LDC) is shown in Figure 3. The load steps and the associated probabilities are given in Table VII.

Table IV: Transmission line fault probabilities

\begin{tabular}{|l|c|}
\hline \multicolumn{1}{|c|}{ Type of Fault } & Probability of occurrence \\
\cline { 2 - 2 } Single line to ground fault & 0.70 \\
\hline Double line fault & 0.15 \\
\hline Double line to ground fault & 0.10 \\
\hline Three phase fault & 0.05 \\
\hline
\end{tabular}

Table V: Transmission line fault location probabilities

\begin{tabular}{|c|c|}
\hline $\begin{array}{c}\text { Fault location } \\
\text { (p.u. Line length) } \\
0.0\end{array}$ & Probability \\
\hline 0.5 & $1 / 3$ \\
\hline 1.0 & $1 / 3$ \\
\hline
\end{tabular}

Table VI: Fault clearing time probability distribution data

\begin{tabular}{|c|c|c|c|}
\hline $\begin{array}{c}\text { Line } \\
\text { No. }\end{array}$ & $\begin{array}{c}\text { Type of } \\
\text { Distributio } \\
\mathrm{n}\end{array}$ & $\begin{array}{c}\text { Mean } \\
\text { Clearing } \\
\text { Time }(\mathrm{s})\end{array}$ & $\begin{array}{c}\text { Standard } \\
\text { Deviation } \\
(\mathrm{s})\end{array}$ \\
\cline { 2 - 4 } & Normal & 0.3 & 0.03 \\
\hline 2 & Normal & 0.4 & 0.04 \\
\hline 3 & Normal & 0.4 & 0.04 \\
\hline 4 & Normal & 0.2 & 0.02 \\
\hline 5 & Normal & 0.2 & 0.02 \\
\hline 6 & Normal & 0.3 & 0.03 \\
\hline 7 & Normal & 0.4 & 0.04 \\
\hline 8 & Normal & 0.2 & 0.02 \\
\hline 9 & Normal & 0.2 & 0.02 \\
\hline
\end{tabular}

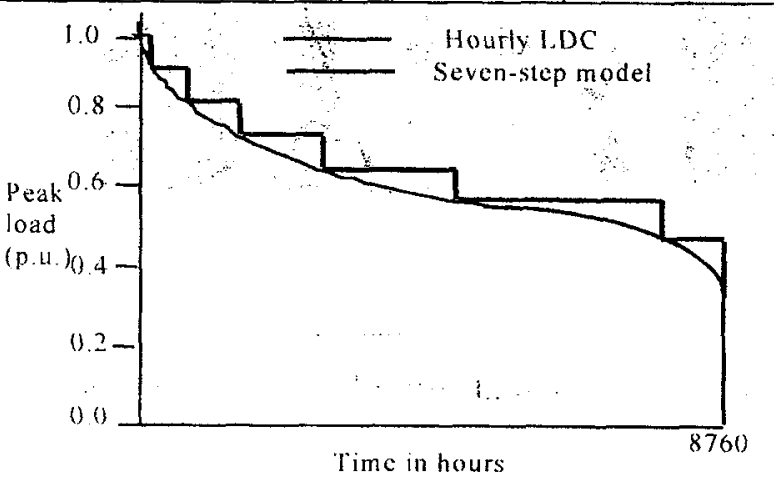

Figure 3: Seven-step load model for RBTS 
It is assumed in the analysis that the loads at different buses vary in proportion to the total system load. The weighted probability of stability for all the RBTS transmission lines are shown in Figure 4 to 6 . Figure 7 shows the overall probability of stability for the system. Both annual and annualized indices are presented in these figures.

Table VII: Probability of different load levels

\begin{tabular}{|c|c|c|}
\hline \hline Load Step & \% Load & Probability \\
\cline { 2 - 3 } 1 & 40 & 0.03651557 \\
\hline 2 & 50 & 0.22630495 \\
\hline 3 & 60 & 0.21554486 \\
\hline 4 & 70 & 0.23202839 \\
\hline 5 & 80 & 0.16540751 \\
\hline 6 & 90 & 0.11103480 \\
\hline 7 & 100 & 0.01316392 \\
\hline
\end{tabular}

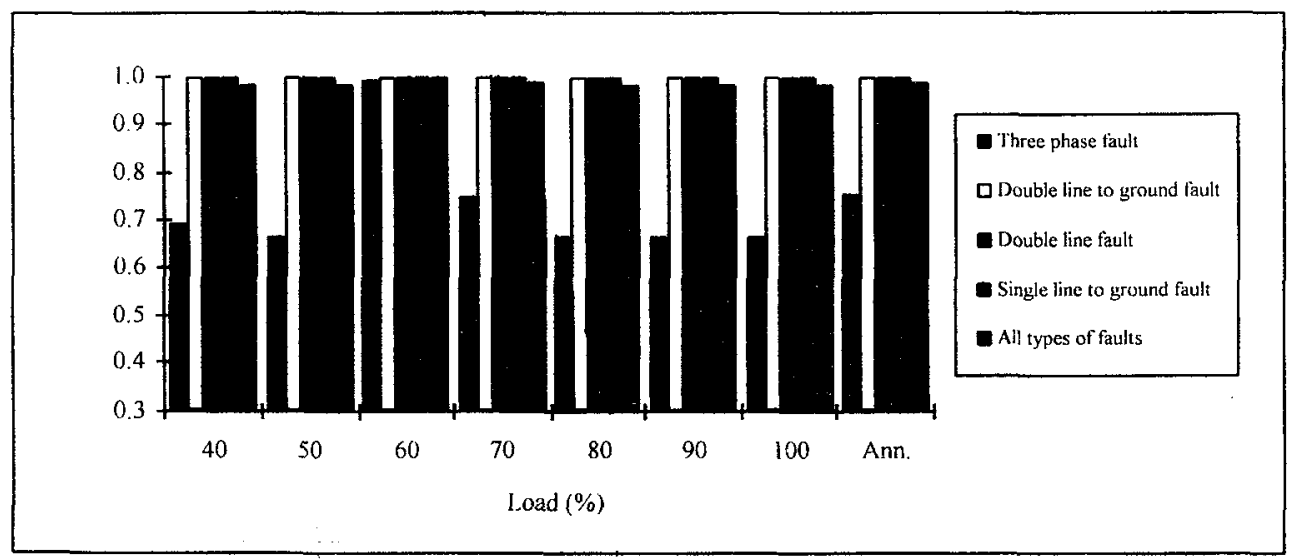

Figure 4: Weighted probability of stability for line \#1 and line \#6

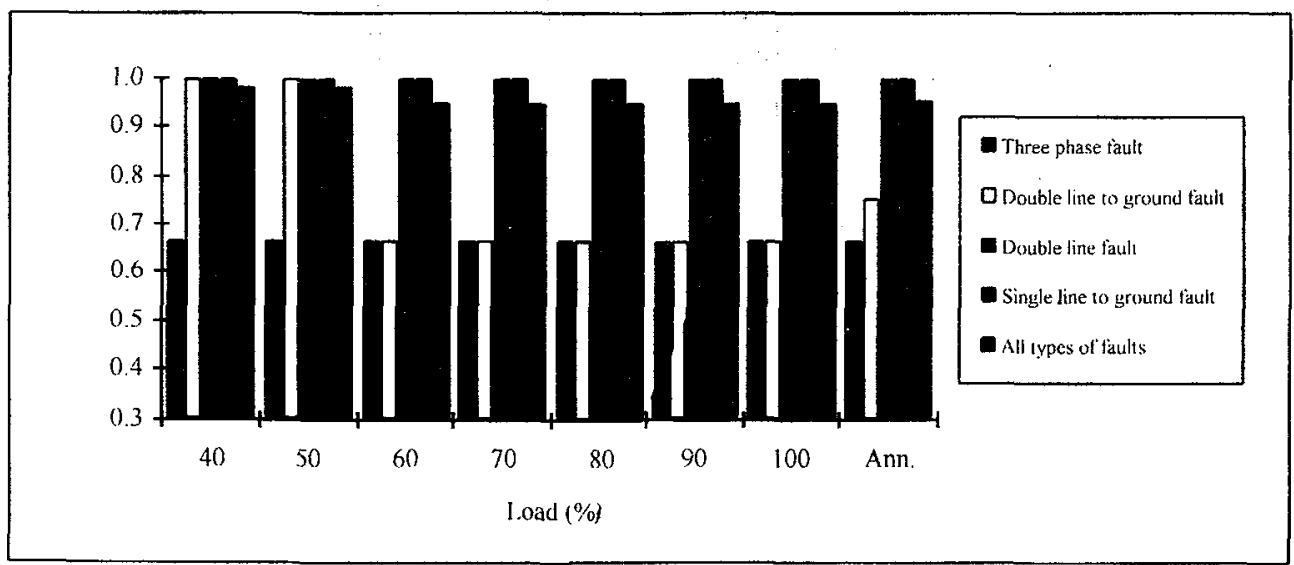

Figure 5: Weighted probability of stability for line \#2 and line \#7 


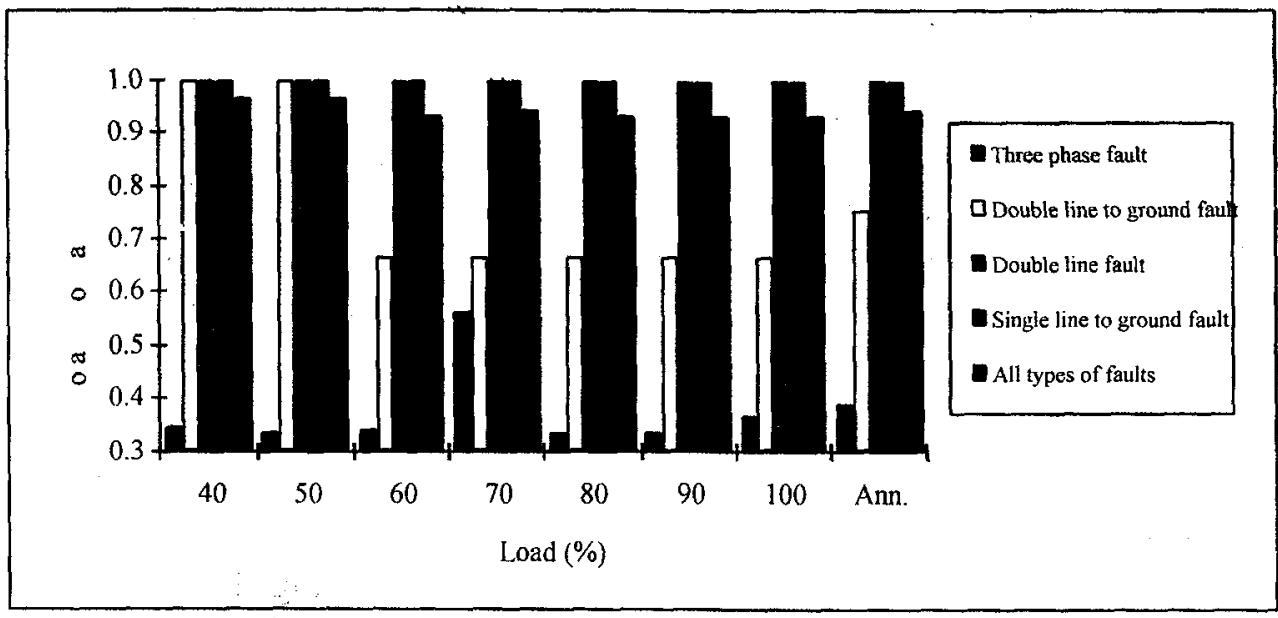

Figure 6: Weighted probability of stability for line \#3

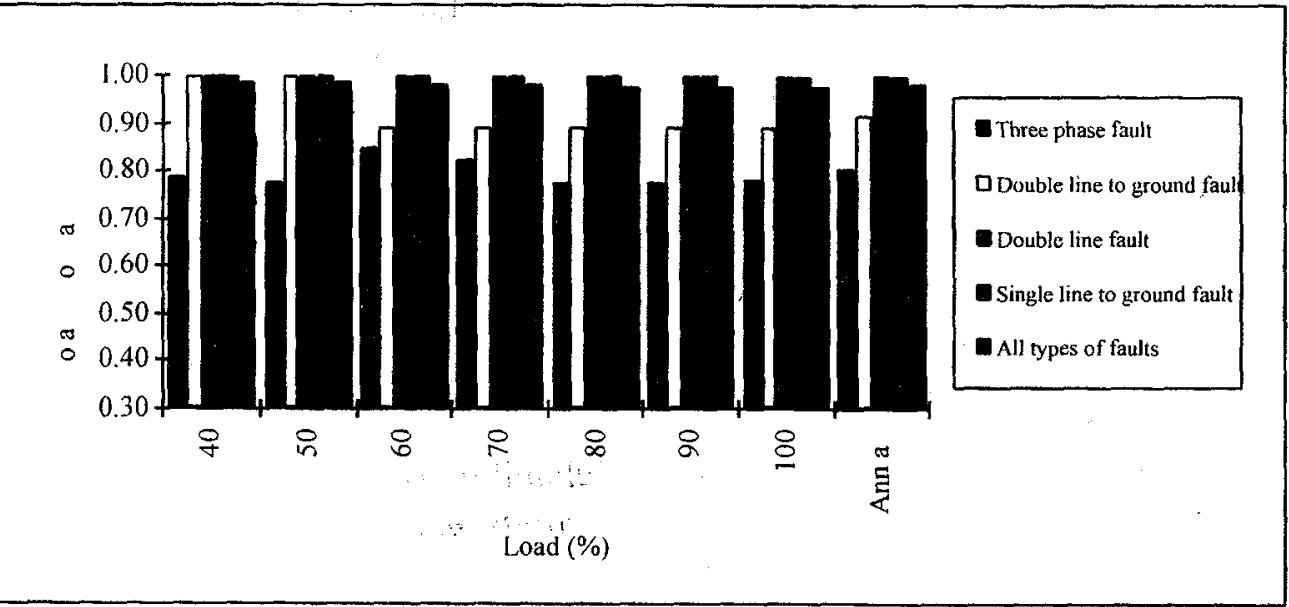

Figure 7: Overall probability of stability for the RBTS

It is clear from these figures that three phase faults have the lowest probability of stability while single phase and phase to phase faults have a probability of stability of unity as the system is stable for any single line or two line fault occurring at any system location. Figures 4 to 6 also show that Lines 1,2,3,6 and 7 are the most critical lines in the system. This is due to the fact that these lines are connected to the generator buses. It is found also that the probability of stability for lines $4,5,8$ and 9 is equal to unity. This is also due to the fact that those lines are far away from the generator busses.

The probability of stability is the lowest for three phase faults on line 3 , which links the two generating stations. This can clearly be seen from Figure 6 . The annual index for all fault types on line 3 is also the lowest value as both three phase and line to line to ground faults have probabilities of stability much lower than unity for these lines. One way to improve this, of course, is to provide a quicker clearing time for faults in this line. This can be easily simulated and evaluated by changing either the mean clearing time or the standard deviation or both for the line 3 fault clearing time probability distribution 
The probabilistic framework proposed and illustrated in this paper extend the basic concepts associated with teaching transient stability analysis. The approach incorporates system consideration rather than simply associating stability evaluation with a worst case scenario. There are many possible fault locations and a number of basic fault types. Each of these events have probabilities of occurrence associated with them. The probabilistic nature of system operation and performance is an important phenomenon which should be discussed and appreciated in an undergraduate or graduate power system engineering program.

\section{CONCLUSIONS}

This paper extends the basic data and available information relating to the RBTS. It also illustrates a basic procedure for calculating both annual and annualized transient stability indices for each line and for the overall system. This procedure and the resulting indices provide the ability to quantitatively assess the likelihood of system instability due to the occurrence of a transmission line fault. It permits the recognition of uncertainty in transient stability analysis and provides the ability to perform sensitivity studies which include fault probabilities, locations and clearing times. Transient stability analysis is an integral component in a basic undergraduate and graduate power curriculum [4]. The basic concepts can be easily extended to include the residual uncertainties which exist in actual practice using the approach described in this paper.

\section{REFERENCES}

[1] R. Billinton, S. Kumar, et al, "A Reliability Test System for Educational Purposes - Basic Data", IEEE Transactions on Power Systems, Vol. 4, No. 3, pp. 1238-1244, Aug. 1989.

[2] R. Billinton and R.N. Allan, Reliability Evaluation of Power Systems, Plenum Press, New York, 1984.

[3] R. Billinton and R.N. Allan, Reliability Assessment of Large Electric Power Systems, Kluwer Academic Publishers, Boston, 1988.

[4] P.M. Anderson and A.A. Fouad, Power System Control and Stability, The Iowa State University Press, Ames, Iowa, 1977.

[5] R. Billinton and P.R.S. Kuruganty, "A Probabilistic Assessment of Transient Stability in a Practical Multimachine System", IEEE Transactions on Power Apparatus and Systems, Vol 100, No. 7, Jul. 1981, pp. 3634-3642.

[6] Billinton, R. and Kuruganty, P.R.S., "An Approximate Method for Probabilistic Assessment of Transient Stability", IEEE Transactions on Reliability, Vol R-28, No. 3, Aug. 1979. pp. 255-258.

17] Billinton, R. and Kuruganty, P.R.S., "Probabilistic Evaluation of Transient Stability in MultiMachine Power System", Proc. IEE, Vol. 126, 1979, pp. 255-258. 
[8] R. Billinton and P.R.S. Kuruganty, "A Probabilistic Index for Transient Stability", IEEE Transactions on Power Apparatus and Systems, Vol 99, 1980, pp. 195-206.

[9] P.R.S. Kuruganty and R. Billinton, "Protection System Modeling in A Probabilistic Assessment of Transient Stability.", IEEE Transactions on Power Apparatus and Systems, Vol 100, May 1981, pp. 2163-2170.

[10] Y. Hsu and C. Chang, "Probabilistic Transient Stability Studies Using the Conditional Probability Approach", IEEE Transactions on Power Systems, Vol. 3, No. 4, Nov. 1988, pp. 1565-1572.

[11]P.M. Anderson and A. Bose, "A Probabilistic Approach to Power System Stability Analysis", IEEE Transactions on Power Apparatus and Systems, Vol 102, No. 8, Aug. 1983., pp. 2430-2439.

[12]B. Porretta, D. Kiguel, G. Hamoud and E. Neudorf, " A Comprehensive Approach for Adequacy and Security Evaluation of Bulk Power Systems", IEEE Transactions on Power Systems, Vol. 6, No. 2, May 1991, pp. 433441. 
نظام الاختبار الاحتمالي للأهداف التطليمية لدراسة الاتزان العابر الاحتمالي

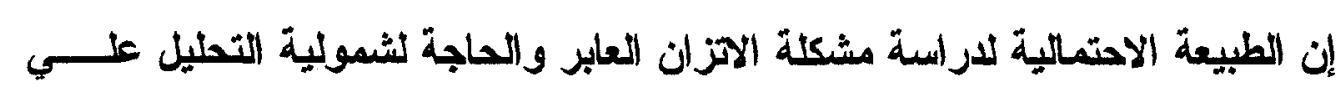

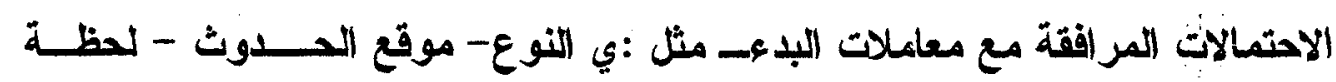
زوال الخطأ قد تم اعتباره في بعض الأحيان. ولكن هده المعاملات لم يتم احتسابها نهائيا (أو نادرا) عند تكوين مجموعة الأسـس الكس المر افقة لبرنامج تطيمي لنظم القوي العهريائية.

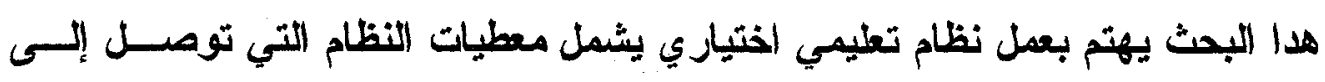

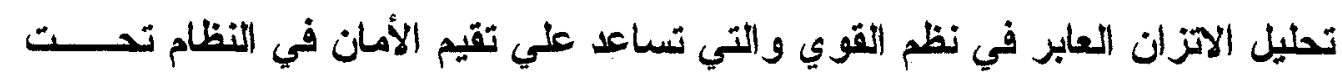

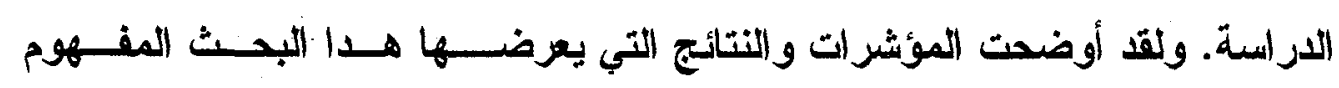

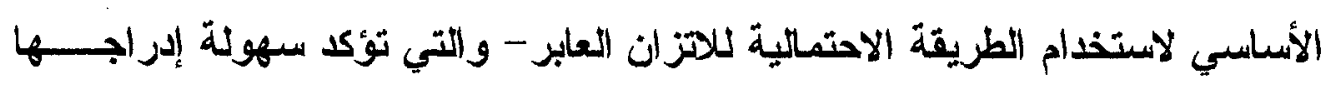
ضمن دراسة وثوقية أو اتزان نظم القوي في برنامج تعليمي. 